\title{
Association between the Unterberger-Fukuda test and vectoelectronystagmography
}

Ana Cecília Grilli Fernandes(1) Nelma Ellen Zamberlan-Amorim ${ }^{(1)}$ Sthella Zanchetta ${ }^{(1)}$

(1) Universidade de São Paulo - USP Ribeirão Preto (SP), Brasil. Research support source: Program of Scientific Initiation - National Council for Scientific and Technological Development " (CNPq Grant No. 146503/2011-2).

Conflict of interests: Nonexistent

\section{(c) (i)}

Received on: September 29, 2017 Accepted on: January 25, 2018

Mailing address:

Sthella Zanchetta

Departamento de Oftalmologia,

Otorrinolaringologia e Cirurgia de Cabeça e Pescoço, Hospital das Clínicas,

Faculdade de Medicina de Ribeirão Preto, Universidade de São Paulo - USP Avenida Bandeirantes, 3900, $12^{\circ}$ andar Monte Alegre

CEP: 14049-900 - Ribeirão Preto, São

Paulo, Brasil

E-mail: zanchetta@fmrp.usp.br

\section{ABSTRACT}

Purpose: to study and characterize anteroposterior and angular deviations in the Unterberger-Fukuda Test (UFT) in relation to the results of the caloric tests in patients complaining of dizziness or vertigo.

Methods: 44 subjects —-men and women between 20 and 79 years of age - who had symptoms of vertigo or dizziness and had been referred for vectoelectronystagmography were examined. The exclusion criteria were gait difficulties arising from orthopedic and/or spinal disorders, and syndromes or neurological diseases that affect balance. Two procedures were performed: vectoelectronystagmography and UFT.

Results: the caloric test showed that $25.00 \%$ of the patients had hyporeflexia-the most frequent result. In the open-eyes UFT, only $2.30 \%$ presented altered results in anteroposterior displacement. In the closed-eyes test, the equivalent value was $31.80 \%$. Anteroposterior deviation showed a greater correlation with age than the angular one. Abnormal results in the caloric test were associated with the UFT.

Conclusion: the results of the closed-eyes UFT were associated with the caloric test. Anteroposterior deviation was correlated with age, while angular deviation was not.

Keywords: Postural Balance; Dizziness; Vertigo; Electronystagmography; Adult 


\section{INTRODUCTION}

The interaction between the vestibulocochlear apparatus, vision, and proprioception, coordinated by the central nervous system (CNS), maintains body balance. As a result, the symptom of imbalance can have many causal factors, including dizziness, vertigo, and/or others ${ }^{1}$. It follows that the diagnosis of subjects with imbalance is a multidisciplinary challenge.

When a patient reports dizziness and/or vertigo, physicians should assess the vestibulocochlear system $^{2}$. To this end, they often use electrophysiological recordings of corneal-retinal potential during visual and labyrinthine stimulation to evaluate the vestibular pathways. This procedure is most commonly performed using vectoelectronystagmography $(\text { VENG) })^{3,4}$.

VENG is a mandatory examination that is preceded by a careful recording of clinical history, and frequently by rapid tests 5 that were called "the bedside assessment of the vestibular system" by McCaslin, Dundas, and Jacobson $(2016)^{6}$. These tests aim to evaluate the function of the various components of balance, without the need for measurements using equipment. They include the following: (1) the vestibulo-ocular and vestibular spinal reflex test, (2) the spontaneous nystagmus test, (3) the head-impulse test, (4) the head shake test, and (5) the Unterberger-Fukuda test (UFT).

In particular, the UFT was developed in a series of studies and reports that were carried out at different times by its eponymous physicians. First, Unterberger reported that patients with inner ear lesions have a fall tendency when they alternately lift their legs ${ }^{5}$. Fukuda later defined the number of steps, and added forward, backward, and lateral movements ${ }^{7}$. For these reasons, the UFT is also called the Fukuda Step Test or the Fukuda-Unterberger Step Test ${ }^{5}$; all these names refer to the completion of 50-100 steps, in place, with slight variations.

In recent years, studies on the effectiveness, sensitivity, specificity, and reproducibility of several examinations and/or tests to identify and characterize the symptoms of balance disorders, including the UFT, have been reported in the literature ${ }^{8-12}$.

The proponents of the test posited that it would reveal unilateral vestibular lesions by exposing gait deviations ${ }^{7}$. This proposal was studied later by other groups $^{9,13}$. The sensitivity of the UFT for detecting unilateral vestibular deficit was described as $50.00 \%$ when compared to the caloric reflex test alone, and as $70.00 \%$ when compared to combined analysis using the head shake and caloric reflex tests, when the gait test was carried out with the same direction of deviation as in the other two tests ${ }^{13}$. In another study, the UFT showed a positive association with the presence of severe hyporeflexia, with the severity being determined by calculation of the percentage difference between the results of the two ears in the caloric reflex test ${ }^{11}$. The laterality of the test deviation corresponding to the ipsilateral labyrinthine alteration is a function of the exit of the vestibular spinal pathway, which exerts ipsilateral tonic influence on the muscles of the lower limbs, resulting in lower unilateral labyrinthine hyperreflexia to that tonic influence on the respective side of the lesion ${ }^{14}$.

Like any behavioral test, several variables can influence the results of the UFT, including the age of the patient, because gait deviation in the elderly is larger and more frequent than in younger adults ${ }^{9}$. Another variable that can influence the results of the UFT is gait speed: slow gait is more sensitive than faster gait speed ${ }^{15}$.

Despite this, the UFT is still used in studies that aim to verify balance, with or without vestibular involvement ${ }^{16}$. For example, it was used to identify balance difficulties in young patients with idiopathic scoliosis ${ }^{16}$, and to assess the effectiveness of oculomotor training in mal de débarquement syndrome ${ }^{17}$.

Given that deviation in the UFT may be associated with unilateral labyrinthine hyperreflexia, we aimed to describe the results of the test in cases of anteroposterior and angular deviations in subjects complaining of dizziness and vertigo, and to verify that the caloric reflex test is positively associated with age.

\section{METHODS}

This was a prospective, transversal, documental, observational study, approved by the Research Ethics Committee of the Clinical Hospital and the Faculty of Medicine of Ribeirão Preto, University of Sao Paulo (No. 11239/2011). All volunteers signed a Free and Informed Consent Form.

Altogether, 44 adults and elderly patients, of both sexes, were studied. They were recruited from the outpatient otoneurology department of the institution.

The inclusion criteria were (1) referral of the subjects from the abovementioned outpatient clinic, (2) complete otorhinolaryngology evaluation, (3) documentation of medical management in the hospital chart, and (4) referral for VENG. 
The exclusion criteria were (1) the presence of gait difficulties arising from orthopedic and/or column alterations, (2) syndromes and neurological diseases that affect balance (e.g. Parkinson's Disease); (3) a medical diagnostic hypothesis of central dizziness and/ or vertigo; (4) a decrease in visual acuity, of whatever nature, that could not be corrected using lenses; and (5) the presence of the following changes in VENG: irregular calibration, spontaneous nystagmus or semi-spontaneous nystagmus with open eyes, or of congenital nystagmus with closed eyes that had an angular velocity greater than 7 degrees per second.

The two procedures-UFT and VENG - respectively, were carried out at the same time and on the same day. The UFT material was made with three concentric circles of radiuses of 50,100 , and $150 \mathrm{~cm}$ and with angles of 30, 60, and 90 degrees; these materials were fixed to the floor of the examination room. All the participants were positioned in the center of the drawing with both arms raised and instructed to perform 50-100 steps, first with open eyes and then with closed eyes. All procedures were performed according to guidelines by Brazilian experts in the field ${ }^{18}$.

The results obtained from the UFT were classified as either normal or altered. They were classified as altered when the volunteer presented an anteroposterior displacement (APD) equal to or greater than 50 $\mathrm{cm}$, or an angular deviation (AD) equal to or greater than $30 \circ$, as described by Bento, Miniti, and Marone ${ }^{19}$. This analysis enabled four response modalities: $A D$ and APD in the open-eyes test, and AD and APD in the closed-eyes test.

The VENG was performed using a Neurograff brand appliance and thermal stimulations with water. The sequence of the tests was as follows: (1) calibration of ocular movements; (2) assessment of spontaneous nystagmus with open and closed eyes; (3) semispontaneous nystagmus test; (4) saccadic movement test; (5) pendular nystagmus test; (6) optokinetic test; (7) caloric reflex test.
The results of VENG were considered an independent variable, and the results of each test were interpreted individually and categorized as either normal or altered. The parameters used were those suggested by the equipment manufacturer, and the interpretation of the results as either normal and altered followed the manual of the Brazilian Scientific Society of Speech Pathology $(\mathrm{SBFa})^{18}$. Sex, age, duration of symptoms in months, and current use or non-use of drugs for vertigo/dizziness were assessed and also considered as independent variables.

Fisher's exact test was used to assess whether abnormal UFT results were associated with the vestibular tests. The occurrence of deviations from the UFT with age was also assessed using Pearson's correlation (Shapiro-Wilk test), as the test results displayed a normal distribution. In all analyses, a 5\% significance level was adopted and is highlighted in the tables using an asterisk $\left(^{*}\right)$.

\section{RESULTS}

In total, 44 volunteer patients between 20 and 79 years old were evaluated. The patients were divided into five age groups: Group 1 (G1; 20-39 years; $n=$ 9); Group 2 (G2; 40-49 years; $n=8$ ); Group 3 (G3; 50-59 years; $n=10)$; Group 4 (G4; 60-69 years; $n=$ 11); Group 5 (G5; $70-79$ years; $n=6$ ). In four of the five groups, there was a predominance of women: $\mathrm{G} 1$, 100.00\%; G2, 87.50\% (7/8); G4, 81.90\% (9/11); G5, $83.30 \%(5 / 6)$.

The elapsed time (in months) from the beginning of the dizziness and/or vertigo to the date of the evaluation (Figure 1) was assessed. The shortest time in a single patient was one 1 month, which occurred in G1 and G2 - the lower age range; the longest time was 342 months, observed in G3 (50-59 years). The mean times occurred in the following order, from highest to lowest: G3, G4, G1, G5, and G2. 


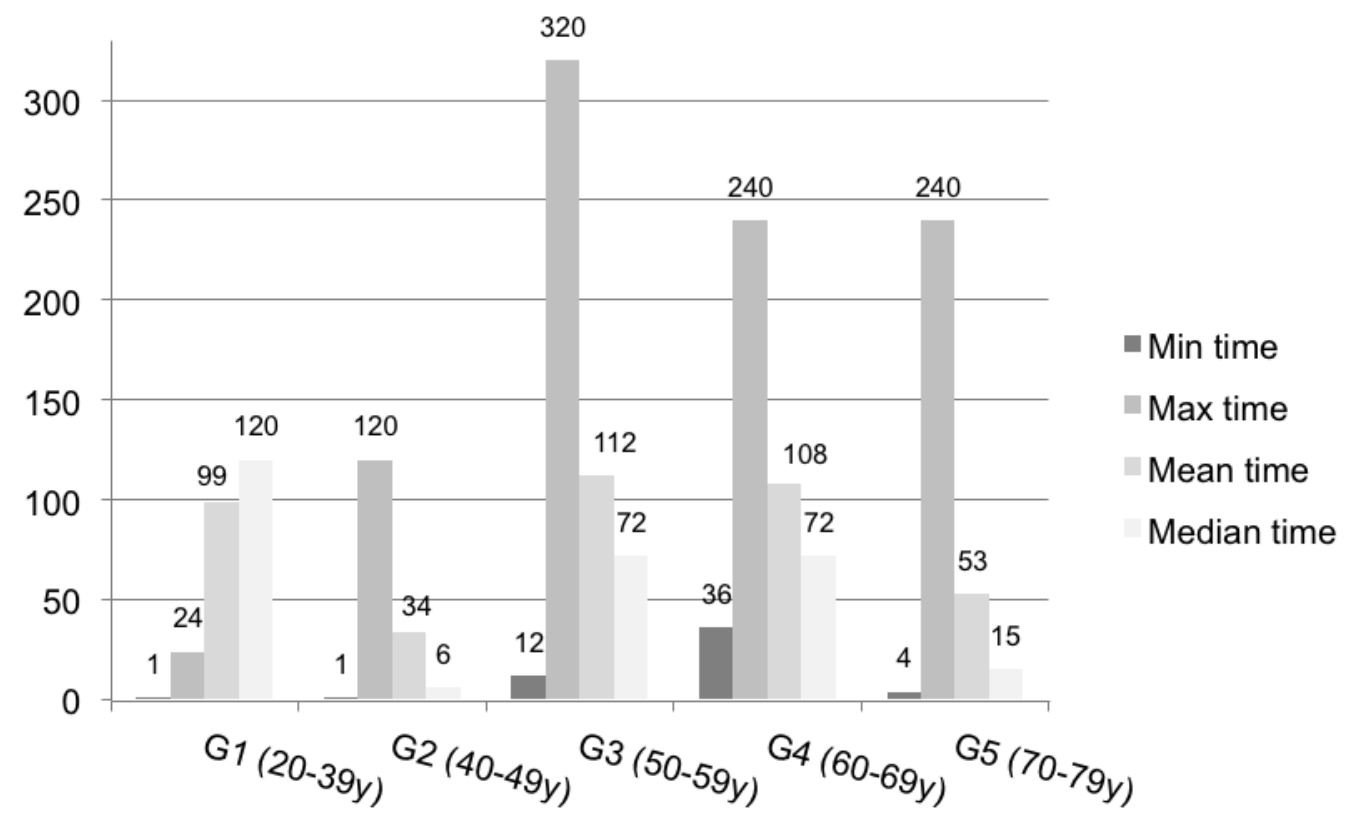

G1 (20-39 years old) = Group 1 (20-39 years old); G2 (40-49a) = Group 2 (40-49 years old); G3 (50-59a) = Group 3 (50-59 years old); G4 (60-69a) = Group 4 $(60-69$ years old $) ; G 5(70-79 a)=$ Group 5 (70-79 years old); min time = minimum duration of symptoms; max time = maximum duration of symptoms; mean time $=$ mean duration of symptoms in the entire sample; median = median time of symptom.

Figure 1. Time, in months, between the beginning of symptoms and vectoelectronystagmography

Among the 44 subjects, $79.50 \%(n=35)$ used medications for dizziness and/or vertigo. When these results were analyzed according to age (Figure 2), it was found that all age groups used medications, and the highest and lowest age range displayed the highest and lowest frequencies of use, respectively (G5, 100.00\%; G1 = 55.6\%).

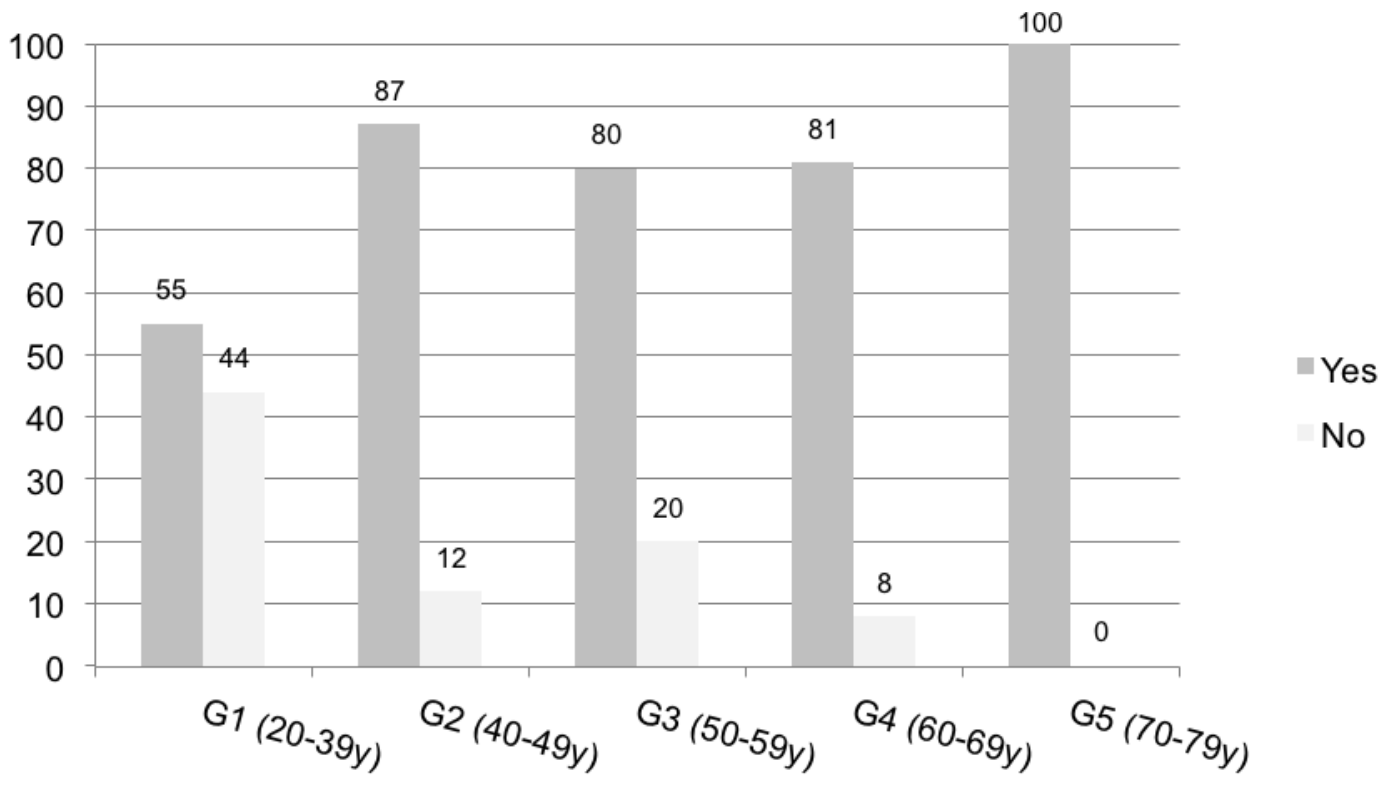

G1 $(20-39$ years old $)=$ Group 1 (20-39 years old); G2 (40-49 years old) = Group 2 (40-49 years old); G3 (50-59 years old) = Group 3 (50-59 years old); G4 (6069 years old $)=$ Group 4 (60-69 years old); G5 (70-79 years old $)=$ Group 5 (70-79 years old); Yes = use of medications; No = no use of medication.

Figure 2. Distribution, in percentage, of the use of medications for dizziness and vertigo 
All 44 subjects presented regular calibration in VENG, absence of spontaneous nystagmus, and semi-spontaneous open-eyes and closed-eyes nystagmus. There were no abnormal results with regard to ocular motricity.

In the vestibular caloric reflex test, $29.55 \%$ ( $n=$ 13) of the patients had abnormal results. Among the possible interpretations, $25.00 \%$ (11/44) had hyporeflexia, 2.27\% (1/44) hyperreflexia, and 2.27\% (1/44) areflexia (Table 1). Given that vestibular areflexia suggests CNS involvement, this patient from the G3 was excluded from the remaining analysis. Thus, the final sample comprised 43 subjects, and G3 contained nine subjects.

Table 1. Results of the vestibular tests using vectoelectronystagmography in relation to the type of alteration in the caloric reflex test in each age group

\begin{tabular}{|c|c|c|c|c|c|}
\hline \multirow[b]{2}{*}{$\begin{array}{l}\text { Age Group/ } \\
\text { Range }\end{array}$} & \multicolumn{2}{|c|}{ Caloric reflex test } & \multicolumn{3}{|c|}{ Type of abnormal in the caloric reflex test } \\
\hline & $\begin{array}{c}\text { Normal } \\
\mathrm{n} / \%\end{array}$ & $\begin{array}{c}\text { Abnormal } \\
\mathrm{n} / \%\end{array}$ & $\begin{array}{c}\text { Hyperreflexia } \\
\text { n/\% } \\
\end{array}$ & $\begin{array}{c}\text { Hyporeflexia } \\
\text { n/\% }\end{array}$ & $\begin{array}{c}\text { Areflexia } \\
\mathrm{n} / \%\end{array}$ \\
\hline $\begin{array}{c}\mathrm{G} 1(\mathrm{n}=9) \\
20-39 \text { years }\end{array}$ & $7 / 78.00$ & $2 / 32.00$ & $1 / 50$ & $1 / 50.00$ & $0 / 0.00$ \\
\hline $\begin{array}{c}\text { G2 }(n=8) \\
40-49 \text { years }\end{array}$ & $7 / 87.50$ & $1 / 1.50$ & $0 / 0.00$ & $1 / 100.00$ & $0 / 0.00$ \\
\hline $\begin{array}{c}\text { G3 }(n=10) \\
50-59 \text { years }\end{array}$ & $7 / 70.00$ & $3 / 30.00$ & $0 / 0.00$ & 2/66.50 & $1 / 33.50$ \\
\hline $\begin{array}{c}G 4(n=11) \\
60-69 \text { years }\end{array}$ & $6 / 54.50$ & $5 / 45.50$ & $0 / 0.00$ & $5 / 100.00$ & $0 / 0.00$ \\
\hline $\begin{array}{c}\mathrm{G} 5(\mathrm{n}=6) \\
70-99 \text { years }\end{array}$ & $4 / 67.00$ & $2 / 33.00$ & $0 / 0.00$ & 2/100.00 & $0 / 0.00$ \\
\hline $\begin{array}{c}\text { Total } \\
(\mathrm{n}=44)\end{array}$ & $31 / 70.45$ & $13 / 29.55$ & $1 / 2.27$ & $11 / 25.00$ & $1 / 2.27$ \\
\hline
\end{tabular}

There was only one altered result $(2.33 \% ; 1 / 43)$ in the open-eyes UFT. This occurred in the highest age group (G5) in the APD modality $(>50 \mathrm{~cm})$. All other results were within normality (Table 2 ).

Table 2. Results of the open- and closed-eyes Unterberger-Fukuda test in relation to ages 37.5, 33.3 and 27.3

\begin{tabular}{|c|c|c|c|c|c|c|c|c|c|c|c|c|}
\hline \multirow{3}{*}{$\begin{array}{l}\text { Age Group/ } \\
\text { Range }\end{array}$} & \multicolumn{6}{|c|}{ UFT Eyes Open } & \multicolumn{6}{|c|}{ UFT Eyes Closed } \\
\hline & \multicolumn{2}{|c|}{$\begin{array}{c}\text { Anteroposterior } \\
\text { deviation }\end{array}$} & \multicolumn{4}{|c|}{ Angular deviation } & \multicolumn{2}{|c|}{$\begin{array}{c}\text { Anteroposterior } \\
\text { deviation }\end{array}$} & \multicolumn{4}{|c|}{ Angular deviation } \\
\hline & $\begin{array}{c}\leq 50 \mathrm{~cm} \\
\mathrm{n} / \%\end{array}$ & $\begin{array}{c}50-100 \\
\mathrm{~cm}^{*} \mathrm{n} / \%\end{array}$ & $\begin{array}{c}\leq 30^{\circ} \\
\mathrm{n} / \%\end{array}$ & $\begin{array}{c}30^{\circ} .- \\
60^{\circ} . \# \mathrm{n} / \%\end{array}$ & $\begin{array}{c}60^{\circ} .- \\
90^{\circ} . * \mathrm{n} / \% \\
\end{array}$ & $\begin{array}{c}>90^{\circ} . \# \\
\mathrm{n} / \%\end{array}$ & $\begin{array}{c}\leq 50 \mathrm{~cm} \\
\mathrm{n} / \%\end{array}$ & $\begin{array}{c}50-100 \\
\mathrm{~cm}^{*} \mathrm{n} / \% \\
\end{array}$ & $\begin{array}{c}\leq 30^{\circ} . \# \\
\mathrm{n} / \%\end{array}$ & $\begin{array}{c}30^{\circ} .-60^{\circ} . \# \\
\mathrm{n} / \%\end{array}$ & $\begin{array}{c}60^{\circ} .-90^{\circ} . \# \\
n / \%\end{array}$ & $\begin{array}{c}>90^{\circ} . \# \\
\mathrm{n} / \%\end{array}$ \\
\hline $\begin{array}{c}\mathrm{G} 1(\mathrm{n}=9) \\
\text { 20-39 years }\end{array}$ & $9 / 100.00$ & $0 / 0.00$ & $9 / 100.00$ & $0 / 0.00$ & $0 / 0.00$ & $0 / 0.00$ & $9 / 100.00$ & $0 / 0.00$ & $7 / 77.50$ & $1 / 1.25$ & $1 / 1.25$ & $0 / 0.00$ \\
\hline $\begin{array}{c}\mathrm{G} 2(\mathrm{n}=8) \\
40-49 \text { years }\end{array}$ & $8 / 100.00$ & $0 / 0.00$ & $8 / 100.00$ & $0 / 0.00$ & $0 / 0.00$ & $0 / 0.00$ & $7 / 87.50$ & $1 / 12.50$ & $5 / 62.50$ & $2 / 25.00$ & $1 / 12.50$ & $0 / 0.00$ \\
\hline $\begin{array}{c}\mathrm{G} 3(\mathrm{n}=9) \\
50-59 \text { years }\end{array}$ & $9 / 100.00$ & $0 / 0.00$ & $9 / 100.00$ & $0 / 0.00$ & $0 / 0.00$ & $0 / 0.00$ & $8 / 80.00$ & $1 / 11.00$ & $6 / 60.00$ & $1 / 10.00$ & $1 / 11.11$ & $1 / 10.00$ \\
\hline $\begin{array}{l}\mathrm{G} 4(\mathrm{n}=11) \\
60-69 \text { years }\end{array}$ & $11 / 100.00$ & $0 / 0.00$ & $11 / 100.00$ & $0 / 0.00$ & $0 / 0.00$ & $0 / 0.00$ & 8/72.70 & $3 / 27.30$ & 8/72.70 & $2 / 18.20$ & $1 / 9.10$ & $0 / 0.00$ \\
\hline $\begin{array}{c}\mathrm{G} 5(\mathrm{n}=6) \\
70-99 \text { years }\end{array}$ & $5 / 93.40$ & $1 / 16.60$ & $6 / 100.00$ & $0 / 0.00$ & $0 / 0.00$ & $0 / 0.00$ & $5 / 83.30$ & $1 / 16.70$ & $4 / 66.6$ & $0 / 0.00$ & $1 / 16.20$ & $1 / 16.20$ \\
\hline Total & $42 / 97.67$ & $1 / 2.33$ & $43 / 100.00$ & $0 / 0.00$ & $0 / 0.00$ & $0 / 0.00$ & $37 / 86.05$ & 6/13.95 & $30 / 69.83$ & $6 / 13.95$ & $5 / 11.62$ & $2 / 4.60$ \\
\hline
\end{tabular}

\# Deviation values considered altered; UFT = Unterberger-Fukuda Test. 
When the closed-eyes UFT was analyzed for $A D$ and APD in the different groups, G4 presented the highest occurrence of altered results (6/43), followed by both G2 and G3 (4/43 in each case) (Table 2). When we studied the type of deviation, $A D$ was more frequent than APD (30.23\% vs. $13.95 \%)$. Specifically, in patients with $A D$, the occurrence of abnormal results was similar in all groups (G1, 22, 20\%; G2, 37, 50\%; G3, 33, 33\%; G4, 27, 30\%; and G5, 33, 30\%. The highest frequency of abnormal results in patients with APD occurred in G4, with $27.3 \%(3 / 11)$.

Before studying the association between the UFT and caloric reflex test results, we analyzed, in the closed-eyes test only, the correlation between the altered results and the types of deviations as a function of age (Figure 3). The $A D$ results were grouped into only two categories: adequate $(\leq 30$ ) ) and altered (> 309). APD showed a strong correlation with age $(r=0.8119, p=0.0951, \mathrm{Cl}=-0.2479-0.9871)$, which, although not significant, did constitute a tendency. That is, higher ages tended towards a higher occurrence of stepping forwards or backwards. In the case of $A D$, the correlation was only moderate $(r=0.4452, p=0.4525$, $\mathrm{Cl}=-0,7198-0.9531)$. That is, the presence of altered $A D$ results did not fully follow the increase in age.

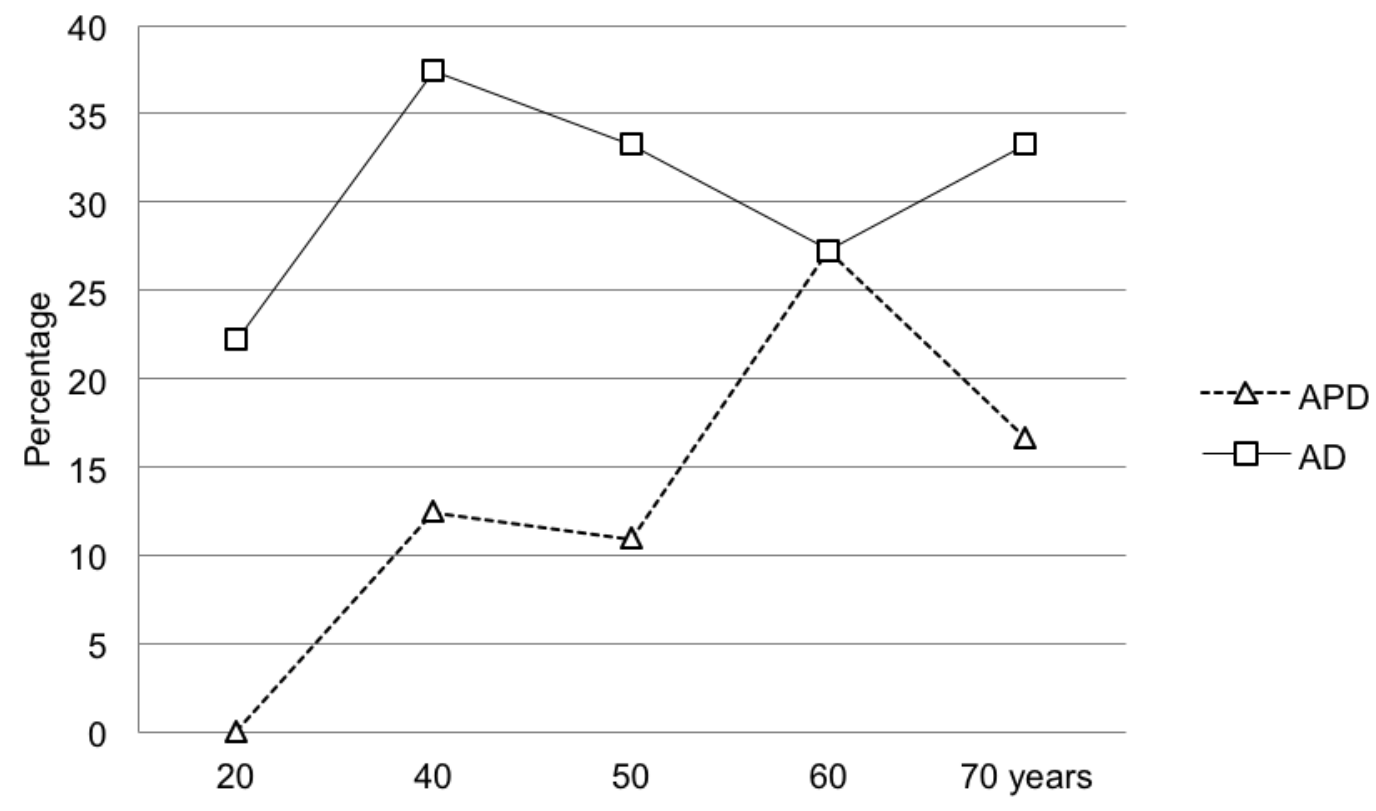

APD = anteroposterior deviation; $A D=$ angular deviation

Figure 3. Correlation between altered Unterberger-Fukuda test results and age

As the open-eyes UFT showed no altered results, there was no need to compare the results of the caloric reflex test. The association between the closed-eyes UFT and the caloric reflex test was significant $(p<$
0.05). Moreover, the patient with altered results in the UFT displayed an eight-fold higher likelihood of having an altered result in the caloric reflex test (Table 3). 
Table 3. Association between the Unterberger-Fukuda and the caloric reflex tests

\begin{tabular}{cccc}
\hline UFT & \multicolumn{2}{c}{ Caloric reflex test } & Total \\
\cline { 2 - 4 } & $\begin{array}{c}\text { Normal } \\
\mathbf{n} / \%\end{array}$ & $\begin{array}{c}\text { Abnormal } \\
\mathbf{n} / \%\end{array}$ & $39(67.50)$ \\
Normal & $25(86.21)$ & $4(13.79)$ & $14(32.50)$ \\
Abnormal & $6(42.86)$ & $8(57.14)$ & $43(100.0)$ \\
Total & $31(72.10)$ & $12(27.90)$ & \\
Fisher's exact test & & $p=0.008^{*}$ OR $=8.333 \mathrm{Cl}=1.766-29.860$ & \\
\hline
\end{tabular}

UFT = Unterberger-Fukuda Test; p-value obtained using Fisher's exact test;

$\mathrm{Cl}=$ confidence interval; $\mathrm{OR}=$ odds ratio

\section{DISCUSSION}

It is important to emphasize that the patients in the present study were volunteers who had complained of dizziness and vertigo and were referred for VENG. There was a predominance of women in all age groups, as reported previously ${ }^{20}$. This finding is commonly attributed to two factors. Firstly, one etiology of vestibular disorders is hormone-related metabolic change, and this is more frequent in women ${ }^{21}$. Secondly, women seek more medical care than men ${ }^{19}$. Nonetheless, we chose not to divide the results by sex, because no previous studies have indicated that the patient's sex can interfere with the UFT ${ }^{12,22}$.

With regard to age, the symptoms of dizziness and/ or vertigo have been reported to affect individuals of all age groups ${ }^{10,16}$; the present study corroborated these findings.

Concerning the duration of symptoms, it appears that they were chronic in all groups except the two lower age groups (20-39 years and 40-49 years). However, the patients with the highest frequency of medication use were those between 40 and 49 years old, who had the lowest minimum symptom value; these were followed by the elderly (70-79 years). The imbalance symptom in this last group may be associated with comorbidities such as cardiovascular and neurological diseases, which are therefore possible etiologies for dizziness in individuals over 60 years old ${ }^{23}$.

The UFT can be performed with open and closed eyes. However, the present study demonstrated that the closed-eyes step presented a higher frequency of altered results, as well as an association with vestibular dysfunction as identified by the caloric reflex test.

Most studies have performed only the closedeyes step, disregarding the open-eyes one ${ }^{12,16,17,22}$. However, none of these studies justified the exclusion of the open-eyes step, although traditional texts do all assert that closed-eyes balance tests are more sensitive $^{24}$. Specifically, tests in which the subject must maintain balance while standing assess vestibulospinal integrity ${ }^{21}$. Open eyes allow the visual pathway to contribute to maintaining balance, while closing the eyes prevents this mechanism from participating in the task, thus increasing the demand on the vestibulospinal pathway ${ }^{1}$.

An association between the UFT and vestibular tests, specifically the caloric reflex test, has already been documented in the case of unilateral vestibular changes ${ }^{11}$. However, the same association has not been observed in the head shake test, which specifically identifies chronic unilateral dysfunctions ${ }^{13}$. With regard to this controversial finding, the literature states that, although unilateral labyrinthine lesions reduce the ipsilateral tonic influence of the vestibulospinal tract in the affected ear ${ }^{14}$, clinicians must also consider lack of homogeneity because there is no standardized criterion for identifying hyporeflexia or in which stage of the vestibular compensation process the patient is ${ }^{11}$.

As already described, the UFT is applied using various parameters. For instance, the number and speed of the steps may differ, and this may explain the lack of homogeneity in results throughout the literature ${ }^{11,12,15,16,25}$. To increase the reliability of the UFT results, several reports have advised (1) removing clocks, fans, and telephones; and (2) performing the test in silence, thus, avoiding any sound localization, as ambient sound can act as a spatial locator and influence the extent of the rotation and mask peripheral vestibular alteration ${ }^{12}$.

Researchers agree that the UFT alone should not be used as a screening instrument or biomarker of imbalance ${ }^{10,16}$, but as an additional procedure in the investigation of the symptom. In this way, the test can add information to be considered in combination with a diagnostic evaluation. 


\section{CONCLUSION}

In adults and elderly patients with complaints of dizziness and/or vertigo, but without clear evidence of impairment in the central nervous system, there was a higher occurrence of altered UFT results in the closed-eyes test, with more frequent AD. The presence of altered APD displayed was strongly correlated with age, while altered $A D$ was not. Altered results in the UFT were associated with the closed-eyes test and the caloric reflex test.

\section{REFERENCES}

1. Horak FB, Shupert C. Função do Sistema Vestibular no Controle Postural. In: Herdman SJ. Reabilitação vestibular. 2a ed. São Paulo: Manole; 2002. p.25- 46.

2. Colafêmina JF. Causas periféricas da vertigem. In: Tratado de Otorrinolaringologia, volume 2. São Paulo: Roca, 2003. p. 425-59.

3. Jacobson GP, Shepart NT, McCaslin DL, Piker EG, Dindas JA. Eye Movement RecordingTechniques. In: Jacobson GP, Shepard NT. Balance Function Assessment and Management. São Diego (CA): Plural Publishing Inc; 2008. p.63-97.

4. Kaylie D, Garrison D, Tucci DL. Evaluation of the patient with recurrent vertigo. Arch Otolaryngol Head Neck Surg. 2012;138(6): 84-7.

5. Grommes C, Conway D. The steppingtest: a stepback in history. J Hist Neurosci. 2011;20(1):29-33.

6. MacCastlin LD, Dundas JA, Jacobson GP. Beside Assessment of the Vestibular System. In: Jacobson GP, Shepard NT. Balance Function Assessment and Management, 2a Ed. São Diego (CA): Plural Publishing Inc; 2016. p.137-62.

7. Fukuda T. The steppingtest: Two phases of the labyrinthine reflex. Acta Otolaryngol. 1959;20(1):95-108.

8. Honaker JA, Janky KL, Patterson JN, Shepard NT. Modified head shake sensory organization test: Sensitivity and specificity. Gait Posture. 2016;49:67-72.

9. Nicole P, Deborah AJ, Yves L. Age-related differences in Fukuda stepping and BabinskiWeiltests, within-dayvariability and test-retest reliability. Aging Clin Exp Res. 2017;29(2):223-30.

10. Cohen HS, Sangi-Haghpeykar H, Ricci NA, Kampangkaew J, Williamson RA. Utility of Stepping
, Walking, and Head Impulses for Screening Patients for Vestibular Impairments. Otolaryngol Head NeckSurg. 2014;151(1):131-6.

11. Honaker JA, Shepard NT. Performanceof Fukuda Stepping Test as a function of the severity of caloric weakness in chronic dizzy patients. J Am Acad Audiol. 2012;23(8):616-22.

12. Munnings A, Chisnall B, OJI S, Whittaker M, Kanegaonkar R. Environmental factors that affect the Fukuda stepping test in normal participants. J Laryngol Otol. 2015;129(5):450-3.

13. Honaker JA, Boismier TE, Shepard NP, Shepard NT. Fukuda Stepping Test: sensitivity and specificity. J Am Acad Audiol. 2009;20(5):311-4.

14. Takemori S, Ida M, Umezu H .Vestibular training after sudden loss of vestibular function. J Otorhinolaryngol Relat Spec. 1985;47(2):76-83

15. Marque B, Colombo G, Muller R, Durstler MR, Dietz $V$, Straumann D. Influence of vestibular and visual stimulation on split-beltwalking. Exp Brain Res. 2007;183(4):457-63

16. Le Berre M, Guyot MA, Agnani O, Bourdeauducq I, Versyp MC, Donze C et al. Clinical balance tests, proprioceptive system and adolescent idiopathic scoliosis. Eur Spine J. 2017;26(6):1638-44

17. Dai M, Cohen B, Smouha E, Cho C. Readaptation of the vestibulo-ocular reflex relieves the mal de debarquement syndrome. Front. Neurol. 2014;124 (5):1-6.

18. Zeigelboim BS, Taguchi CK, Natal CSM, Ganança CF, Ventura DNishino LK et al. Guia Prático de procedimento Fonoaudiológicos na Avaliação Vestibular. In: Bohlsen YA, Zanchetta S, Nishino LK, Natal CSM. Departamento de Audição e Equilíbrio da Sociedade Brasileira de Fonoaudiologia, 2011.

19. Bento RF, Miniti A, Marone SAM. Doenças do Ouvido Interno. In: Bento RF, Miniti A, Marone SAM.Tratado de Otologia. São Paulo: USP, 1998. p.331-64.

20. Bittar RSM, Oiticica J, Bottino MA, Ganança FF, Dimitrov R. Estudo epidemiológico populacional da prevalência de tontura na cidade de São Paulo. Braz. j. otorhinolaryngol. 2013;79(6): 688-98.

21. Bittar RSM. Labirintopatias hormonais: hormônios esteroides, estrógeno e progesterona. Int Arch Otorhinolaryngol. 1997;1(4):32.

22. Paquet $N$, Jehu DA, Lajoie Y. Age-related differences in Fukuda stepping and Babinski-Weiltests within-day variability and test-retestreliability. Aging Clin Exp Res. 2017;29(2):223-30. 
23. Colledge NR, Barr-Hamilton RM, Lewis SJ, Sellar RJ, Wilson JA. Evaluation of investigationsto diagnose the cause of dizziness in elderly people: a community based controlled study. BMJ. 1996;313(7060):788-92.

24. Whitney S, Herdman SJ. Avaliação Fisioterapêutica da Hipofunção Vestibular. In: Herdman SJ. Reabilitação vestibular. 2a ed. São Paulo: Manole; 2002. p.329-47.

25. Zhong X, Yost WA. Relationship between Postural Stability and Spatial Hearing. J Am Acad Audiol. 2013;24(9):782-8. 